\title{
COMUNICAÇÃO
}

\section{TESTE DE ALELISMO ENTRE OS MUTANTES DE AMADURECIMENTO ALCOBAÇA E NON-RIPENING EM TOMATEIRO}

\author{
Allelism test between the alcobaça and non-ripening mutants in tomato plants \\ Flavio Rodrigo Gandolfi Benites ${ }^{1}$, Wilson Roberto Maluf ${ }^{2}$, Luciano Vilela Paiva ${ }^{3}$, \\ Marcos Ventura Faria ${ }^{4}$, Valter Carvalho Andrade Junior ${ }^{5}$, Luciano Donizete Gonçalves ${ }^{6}$
}

\begin{abstract}
RESUMO
Desde o início da década de 1980, são relatadas na literatura divergências quanto às relações de alelismo ou não entre os mutantes de amadurecimento de frutos de tomateiro denominados alc (= alcobaça) e nor (=non-ripening). Para dirimir tais dúvidas, foi realizado um teste de alelismo entre os genes considerados. Foram avaliadas 364 plantas $\mathrm{F}_{2}$ provenientes do cruzamento entre as linhagens de tomateiro TOM-559 (alc/alc) e TOM-613 (nor/nor), além de vinte plantas de cada uma das linhagens TOM-559 (alcl alc), TOM-613 (nor/nor), de cada um dos híbridos $\mathrm{F}_{1}$ [(TOM-559 x TOM-613), alc ${ }^{+} /$alc nor nor $^{+}$, F $\mathrm{F}_{1}$ [(Floradade $\mathrm{x}$ TOM-559), alc $c^{+} /$alc nor ${ }^{+} /$nor $\left.^{+}\right]$e $\mathrm{F}_{1}$ [(Floradade x TOM-613), alc $c^{+} /$alc $^{+}$nor ${ }^{+} /$nor $]$, bem como da linhagem de genótipo normal Floradade $\left(\right.$alc $^{+} /$alc $^{+}$ nor ${ }^{+} /$nor $^{+}$rin $^{+} /$rin $^{+}$). TOM-559 e TOM-613 são linhagens isogênicas à cv. Floradade, da qual diferem apenas quanto à presença dos genes alc e nor, respectivamente. Frutos de Floradade colhidos no estádio breaker apresentam coloração vermelha normal quando maduros (fenótipo normal), enquanto frutos de TOM-559 ou de TOM-613 permanecem amarelados ou amarelo-alaranjados (fenótipo mutante). De cada planta, foram colhidos quatro frutos no estádio breaker de maturação, que foram avaliadas quanto ao fenótipo (normal ou mutante) quando maduros. Os resultados dos testes de alelismo indicam que a hipótese mais provável é a de que alc e nor sejam alélicos. Dessa maneira, alc é considerado um terceiro alelo no loco nor, e sugere-se a substituição de seu símbolo para nor ${ }^{A}$.
\end{abstract}

Termos para indexação: Solanum lycopersicon, melhoramento de plantas, tomate longa vida.

\begin{abstract}
Since the early 1980's there are conflicting reports on the possible allelic relations between the tomato ripening mutants alc (=alcobaça) and nor (=non-ripening). In order to end these controversies, a test of allelism between the genes alc and nor was performed. A total of 364 plants of the $\mathrm{F}_{2}$ population between the tomato lines TOM-559 (alc/alc) and TOM-613 (nor/nor) were screened, along with 20 plants each of lines TOM-559 (alc/alc) and TOM-613 (nor/nor), of hybrids $\mathrm{F}_{1}$ [(TOM-559 x TOM-613),

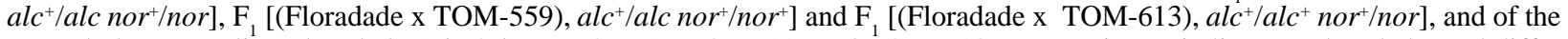
normal phenotype line Floradade $\left(\right.$ alc $^{+} /$alc $^{+}$nor $^{+} /$nor $\left.^{+}\right)$. TOM-559 and TOM-613 are near-isogenic lines to Floradade, and differ from the latter only due to the presence of genes alc and nor, respectively. Floradade fruit harvested at the breaker stage show normal red color (normal phenotype) when fully ripe, whereas fruit of either TOM-559 or TOM-613 remain yellow or yellowish-orange (mutante phenotype). Four fruits per plant were harvested at the breaker stage and subsequently evaluated for their mature fruit color phenotype (normal or mutant). The results of the test of allelism indicate that the most likely hypothesis is that alc and nor are allelic to each other. Therefore, alc was considered to be a third allele at the nor locus, and the symbol nor ${ }^{A}$ was substituted for alc.
\end{abstract}

Index terms: Solanum lycopersicon, plant breeding, tomato shelf life.

(Recebido em 23 de agosto de 2006 e aprovado em 26 de setembro de 2008)

Há na literatura descrição de vários alelos mutantes que interferem no processo natural de amadurecimento dos frutos do tomateiro, retardando o amadurecimento e prolongando a conservação em pós-colheita, dentre os quais destacam-se os alelos rin (ripening inhibitor), nor (non ripening), alc (alcobaça). Vários trabalhos foram realizados, utilizando esses alelos em heterozigose ou duplas combinações heterozigotas, com a finalidade de se aumentar o tempo de conservação dos frutos em póscolheita (Mutschler et al., 1992; Freitas et al., 1998; Andrade Junior et al., 2005; Santos Junior et al., 2005; Faria et al., 2006).

\footnotetext{
${ }^{1}$ Universidade Federal de Campina Grande/UFCG - Pombal, PB

2Universidade Federal de Lavras/UFLA - Departamento de Agricultura/DAG - Cx. P. 3037 - 37200-000 - Lavras, MG - wrmaluf@ufla.br

3Universidade Federal de Lavras/UFLA - Departamento de Química/DQI - Lavras, MG

${ }^{4}$ Universidade Estadual do Centro-Oeste/UNICENTRO - Departamento de Agronomia - Guarapuava, PR

${ }^{5}$ Universidade Federal do Vale do Jequitinhonha e Mucuri/UFVJM - Departamento de Agronomia - Diamantina, MG

${ }^{6}$ Universidade Federal de Lavras/UFLA - Departamento de Agricultura/DAG - Lavras, MG
} 
Desde o início da década de 1980, persiste na literatura uma divergência de resultados entre Lobo et al. (1984), por um lado, e Mutschler (1984), por outro, quanto à relação de alelismo entre alc e nor. Lobo et al. (1984) realizaram o teste de alelismo entre alc e nor, classificando as plantas quanto à coloração dos frutos, como normais (fruto vermelha) ou mutantes (coloração alaranjada ou amarelada). Os frutos da geração $F_{1}$ tinham fenótipo similar ao alcobaça. $\mathrm{Na}$ população $\mathrm{F}_{2}$ não foram encontradas plantas de fenótipo normal, o que foi considerado indicativo de que os genes em estudo são alélicos. Já, Mutschler (1984) realizou o teste de alelismo entre alc e nor por meio de avaliação dos frutos quanto ao tempo de armazenamento, e seus resultados contrastam com o obtido por Lobo et al. (1984). A vida de prateleira dos frutos $F_{1}$ foi, em média, menor que a dos genitores alc e nor. Segundo Mutschler (1984), essa redução no período de armazenamento entre os genitores e a geração $F_{1}$ seria improvável se os dois mutantes fossem alélicos. Nas populações $F_{2}$, foram encontradas plantas com fenótipo normal, o que confirmaria que alc e nor são não-alélicos. A autora concluiu ainda que alc e nor estão ligados, a 17 cM de distância.

Quanto à coloração final dos frutos, Mutschler (1984) relata que na geração $\mathrm{F}_{1}$ (alc $\mathrm{x}$ nor) estes adquirem uma coloração quase normal (vermelha) quando amadurecem na planta, e uma coloração alaranjado-avermelhada quando dela destacados. Ao enfatizar que frutos alclalc adquirem uma coloração amarelada tintada de laranja, e que frutos nor/nor adquirem cor amarelada, fica claro que a autora considera frutos $\mathrm{F}_{1}$ (alc x nor) como tendo fenótipo normal quanto à coloração, em contraste com os homozigotos alc/ alc ou nor/nor cujo fenótipo é mutante [hipótese ortodoxa de não-alelismo de Mutschler (1984)]. Contudo, uma análise literal da descrição pouco precisa da coloração dos frutos $\mathrm{F}_{1}$ (alc x nor) feita pela autora, permite que se considere seu fenótipo como mutante, tendo em vista a variação na expressão fenotípica dos homozigotos nor/nor observada por Tigchelaar \& Barman (1985). Assim, qualquer teste da hipótese de não-alelismo entre alc e nor proposta por Mutschler (1984) deve também levar em consideração a hipótese alternativa, de que $\mathrm{F}_{1}$ (alc x nor) tenha fenótipo mutante (hipótese de não-alelismo alternativa), à luz do observado por Tigchelaar \& Barman (1985).

Conduziu-se este estudo, com o objetivo de determinar a relação de alelismo entre alc e nor, por meio dos testes da hipótese de alelismo proposta por Lobo et al. (1984), bem como das hipóteses implícitas no trabalho de Mutschler (1984). Foram adotadas no presente trabalho para os genes alcobaça e non-ripening as notações alc e nor, respectivamente, na pressuposição inicial de se tratarem de alelos em locos distintos. Uma vez demonstrada a sua relação de alelismo essa notação deverá ser revista, adotando-se, então, a notação nor ${ }^{A}$ para alcobaça, conforme a proposta de Lobo et al. (1984).

O experimento para elucidar a relação de alelismo entre os mutantes alc e nor foi conduzido em estufa plástica na Universidade Federal de Lavras, no ano de 2002. O teste de alelismo foi realizado utilizando-se a população segregante do cruzamento TOM-559 (alc/alc) x TOM- 613 (nor/nor). Foram utilizadas inicialmente 40 parcelas de 10 plantas, totalizando 400 plantas, das quais puderam ser obtidos dados de 364 plantas. De cada planta foram colhidos 4 frutos no estádio breaker de maturação. Os frutos permaneceram armazenados em câmara fria a $15^{\circ}$ $\mathrm{C}$ e umidade relativa de $60 \%$ e foram examinados por 28 dias até determinação da coloração final.

Como testemunha, foram utilizadas 20 plantas das linhagens TOM-559 (alc/alc), TOM-613 (nor/nor) e dos híbrido $\mathrm{F}_{1}[(\mathrm{TOM}-559 \times \mathrm{TOM}-613)=$ alc $/$ alc nor $/$ nor $]$, $\mathrm{F}_{1}\left[\left(\right.\right.$ Flora-Dade $\mathrm{x}$ TOM-559) $=$ alc ${ }^{+} /$alc nor $^{+} /$nor $\left.^{+}\right]$e $\mathrm{F}_{1}$ [(Flora-Dade x TOM-613) $=$ alc $^{+} /$alc $^{+}$nor $/$nor] , bem como da linhagem de genótipo normal Flora-Dade $\left(a c^{+} / a l c^{+}\right.$ nor $^{+} /$nor $\left.^{+}\right)$.

Com base na coloração final de quatro frutos por planta, cada planta foi classificada fenotipicamente como normal (fenótipo semelhante à cultivar Floradade, ou seja, frutos vermelhos quando maduros) ou mutante (fenótipo semelhantes ao das linhagens TOM-559 ou TOM-613, frutos amarelados ou amarelo-alaranjados quando maduros). Foram analisadas três diferentes hipóteses quanto às relações de alelismo entre os mutantes alc e nor:

1) Hipótese de alelismo entre alc e nor admitida por Lobo et al. (1984) e Tigchelaar \& Barman (1985). Admite-se que alc seja alélico a nor, semelhante ou idêntico a este.

2) Hipótese ortodoxa de não-alelismo entre alc e nor, defendida por Mutschler (1984). Esta hipótese admite que alc e nor são genes localizados em locos distintos, no mesmo cromossomo, a uma distância genética de $\mathrm{c}=0,17$ (17 Centimorgans). A autora admite também que o fenótipo da $\mathrm{F}_{1}$ (alc x nor) quanto à coloração dos frutos é considerado normal. Nesse caso, a probabilidade de se obterem plantas de fenótipo normal em $\mathrm{F}_{2}$ seria, pois, $\left[c^{2} / 4+0,5\right]$. A probabilidade de uma população $\mathrm{F}_{2}$ de $\mathrm{N}$ indivíduos, não se detectar nenhuma planta de fenótipo normal seria $p=\left[1-\left(c^{2} / 4+0,5\right)\right]^{\mathrm{N}}=\left[0,5-c^{2} / 4\right]^{\mathrm{N}}$.

3) Hipótese alternativa de não-alelismo entre alc e nor, derivada de uma interpretação alternativa dos dados de Mutschler (1984). Essa hipótese admite que alc e nor são genes localizados em locos distintos, no mesmo 
cromossomo, ligados por uma distância genética de $\mathrm{c}=$ 0,17 (17 Centimorgans), mas interpreta o fenótipo $\mathrm{F}_{1}$ (alc $\mathrm{x}$ nor) descrito pela autora (que não é suficientemente explícita quanto a ele) à luz do descrito por Tigchelaar \& Barman (1985). Essa hipótese admite que o fenótipo do $\mathrm{F}_{1}$ (alc $\mathrm{x}$ nor) quanto à coloração dos frutos é considerado mutante. Nesse caso, a probabilidade de se obterem plantas de fenótipo normal em $\mathrm{F}_{2}$ seria pois, [c(1-c) $\left.+\mathrm{c}^{2} / 4\right]$. A probabilidade de não se detectar nenhuma planta de fenótipo normal em uma população de $\mathrm{N}$ indivíduos seria então: $p=\left[c(1-c)+c^{2} / 4\right]^{N}$.

Foram realizados testes de Qui-quadrado para verificar a aderência às três hipóteses formuladas quanto às possíveis relações de alelismo entre alc e nor, utilizando o programa SAS.

$\mathrm{Na}$ Tabela 1, indicam-se as frequências esperadas dos fenótipos normais e mutantes sob a hipótese de alelismo entre alc e nor, conforme sugerido por Lobo et al. (1984) e Tigchelaar \& Barman (1985) (hipótese 1). Já, as Tabelas 2 e 3 referem-se à hipótese de que alc e nor sejam genes distintos, localizados no mesmo cromossomo a uma distância genética de $\mathrm{c}=0,17$, hipótese levantada por Mutschler (1984) (hipóteses 2 e 3). Na Tabela 2, admite-se a afirmação ortodoxa dessa autora de que os frutos $\mathrm{F}_{1}$ (alc x nor) têm coloração (fenótipo) normal. Na Tabela 3, admite-se alternativamente a interpretação sugerida por Tigchelaar \& Barman (1985) da descrição fenotípica dos frutos $\mathrm{F}_{1}$ (alc x nor) feita por Mutschler (1984), segundo a qual o fenótipo dos frutos $\mathrm{F}_{1}$ (alc $\mathrm{x}$ nor) pode ser considerada mutante.

As hipóteses de não-alelismo entre alc e nor, tanto em sua versão ortodoxa Mutschler (1984) como em sua interpretação alternativa revelaram-se insatisfatórias para explicar os dados obtidos no presente experimento, com uma população de $\mathrm{N}=364$ indivíduos $\mathrm{F}_{2}$ testados.

Em ambas as versões (Tabelas 2 e 3), uma frequência consideravél de indivíduos $\mathrm{F}_{2}$ com fenótipo normal é esperada, mas a frequência obtida para plantas com este fenótipo foi nula. Em ambos os casos, os desvios indicados pelo teste $\mathrm{c}^{2}$ foram altamente significativos. A probabilidade de as hipóteses em questão serem verdadeiras, tendo-se obtidos esses resultados em $\mathrm{F}_{2}$, é de respectivamente $1,33 \times 10^{-122}$ e 4,17 x $10^{-26}$, ambas infinitesimalmente pequenas, o que permite a rejeição das hipóteses de não-alelismo consideradas.

Por outro lado, em se admitindo a hipótese de nãoalelismo como verdadeira, ter-se-ia de admitir que no nível de probabilidade de á $=0,01$, a distância genética entre eles, baseada nos dados obtidos para a população $\mathrm{F}_{2}$ (alc $\mathrm{x}$ nor), deveria ser substancialmente inferior aos $\mathrm{c}=17 \mathrm{cM}$ proposto por Mutschler (1984): a distância deveria ser praticamente nula (em se admitindo $\mathrm{F}_{1}$ com fenótipo normal) ou pelo menos $<1,2 \mathrm{cM}$ (em se admitindo $\mathrm{F}_{1}$ com fenótipo mutante). No nível de probabilidade de á $=$ 0,05, a distância entre os genes alc e nor, em caso de nãoalelismo, somente se poderia explicar na melhor das hipóteses se as distâncias genéticas fossem < 0,8 cM. Já, a hipótese de alelismo entre alc e nor, proposta por Lobo et al. (1984), não pode ser rejeitada, uma vez que as frequências observadas corresponderam exatamente às frequências esperadas (Tabela 1).

Os resultados obtidos nesse teste de alelismo permitem concluir que há uma grande probabilidade de que os genes alc e nor sejam alélicos, conforme sugerem Lobo et al. (1984) e Tigchelaar \& Barman (1985). Segundo Lobo et al. (1984), alc seria um terceiro alelo no loco nor, ao qual se atribuiria o símbolo $n o r^{A}$.

Tabela 1 - Frequências esperadas e observadas de plantas com frutos de fenótipos normal e mutante, admitindo-se a hipótese de alelismo entre alc e nor, proposta por Lobo et al. (1984).

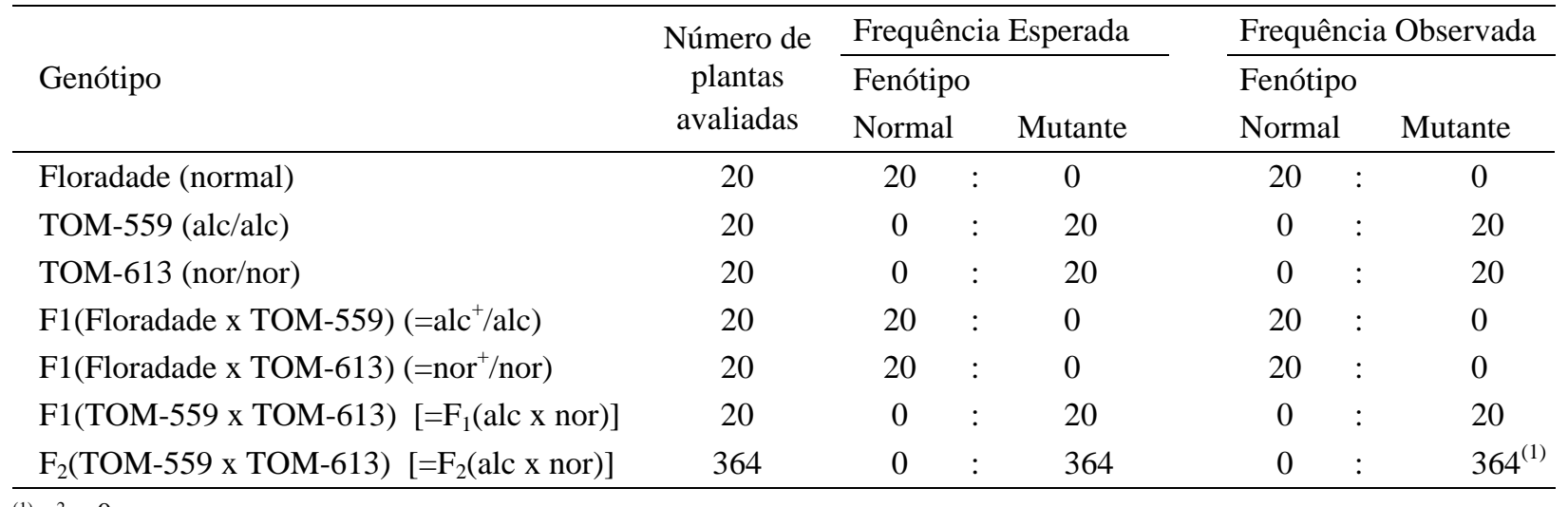


Tabela 2 - Frequências esperadas e observadas de plantas com fenótipos normal e mutante, admitindo-se as hipóteses: (a) de alc e nor serem genes distintos, ligados a uma distância de 17 Centimorgans; (b) o fenótipo do duplo heterozigoto $\left[\mathrm{F}_{1}(\right.$ alc $\mathrm{x}$ nor $\left.)\right]$ ser normal quanto à coloração de frutos.

\begin{tabular}{|c|c|c|c|c|c|c|}
\hline \multirow{3}{*}{ Genótipo } & \multirow{3}{*}{$\begin{array}{l}\text { Número de } \\
\text { plantas } \\
\text { avaliadas }\end{array}$} & \multicolumn{2}{|c|}{ Frequência Esperada } & \multicolumn{3}{|c|}{ Frequência Observada } \\
\hline & & \multicolumn{2}{|c|}{ Fenótipo } & \multicolumn{3}{|c|}{ Fenótipo } \\
\hline & & Normal & Mutante & Normal & & Mutante \\
\hline Floradade (normal) & 20 & 20 & 0 & 20 & $:$ & 0 \\
\hline TOM-559 (alc/alc) & 20 & 0 & 20 & 0 & : & 20 \\
\hline TOM-613 (nor/nor) & 20 & 0 & 20 & 0 & : & 20 \\
\hline F1(Floradade x TOM-559) $\left(=\right.$ alc $^{+} /$alc $)$ & 20 & 20 & 0 & 20 & $:$ & 0 \\
\hline F1(Floradade x TOM-613) (=nor ${ }^{+} /$nor $)$ & 20 & 20 & 0 & 20 & : & 0 \\
\hline F1(TOM-559 x TOM-613) $\left[=\mathrm{F}_{1}(\right.$ alc $\times$ nor $\left.)\right]$ & 20 & 20 & 0 & 0 & $:$ & 20 \\
\hline $\mathrm{F}_{2}(\mathrm{TOM}-559 \times \mathrm{TOM}-613)\left[=\mathrm{F}_{2}(\right.$ alc $\times$ nor $\left.)\right]$ & 364 & 185 & 179 & 0 & : & $364^{(1)}$ \\
\hline
\end{tabular}

${ }^{(1)} \chi^{2}=376,20 * *$.

Tabela 3 - Frequências esperadas e observadas de plantas com fenótipos normal e mutante, admitindo-se as hipóteses: (a) de alc e nor serem genes distintos, ligados a uma distância de 17 CentiMorgan; (b) o fenótipo do duplo heterozigoto $\left[\mathrm{F}_{1}(\right.$ alc $\mathrm{x}$ nor $\left.)\right]$ ser mutante quanto à coloração de frutos.

\begin{tabular}{|c|c|c|c|c|c|c|}
\hline \multirow{3}{*}{ Genótipo } & \multirow{3}{*}{$\begin{array}{l}\text { Número de } \\
\text { plantas } \\
\text { avaliadas }\end{array}$} & \multirow{2}{*}{\multicolumn{2}{|c|}{$\begin{array}{c}\text { Frequência Esperada } \\
\text { Fenótipo }\end{array}$}} & \multirow{2}{*}{\multicolumn{3}{|c|}{$\begin{array}{c}\text { Frequência Observada } \\
\text { Fenótipo }\end{array}$}} \\
\hline & & & & & & \\
\hline & & Normal & Mutante & Normal & & Mutante \\
\hline Floradade (normal) & 20 & 20 & 0 & 20 & : & 0 \\
\hline TOM-559 (alc/alc) & 20 & 0 & 20 & 0 & : & 20 \\
\hline TOM-613 (nor/nor) & 20 & 0 & 20 & 0 & : & 20 \\
\hline F1(Floradade x TOM-559) $\left(=\right.$ alc $^{+} /$alc $)$ & 20 & 20 & 0 & 20 & : & 0 \\
\hline F1(Floradade x TOM-613) $\left(=\right.$ nor $^{+} /$nor $)$ & 20 & 20 & 0 & 20 & : & 0 \\
\hline F1(TOM-559 $\times$ TOM-613) $\left[=F_{1}(\right.$ alc $\times$ nor $\left.)\right]$ & 20 & 0 & 20 & 0 & : & 20 \\
\hline $\mathrm{F}_{2}(\mathrm{TOM}-559 \times \mathrm{TOM}-613)\left[=\mathrm{F}_{2}\right.$ (alc $\times$ nor $\left.)\right]$ & 364 & 54 & 310 & 0 & : & $364^{(1)}$ \\
\hline
\end{tabular}

Lobo et al. (1984) fazem distinções entre os fenótipos condicionados por nor $^{A}$ (alclalc) e nor e indicam ainda, que o fenótipo nor é dominante sobre o fenótipo nor. No presente trabalho, não se pode claramente distinguir os efeitos fenotípicos de nor dos de alc. Assim, os dados presentes não permitem concluir que alc (ou $n o r^{A}$ ) possa ser de fato considerado um alelo distinto do próprio nor.

De qualquer modo, a possibilidade de alc e nor serem genes distintos, mas localizados num mesmo segmento cromossômico bastante pequeno (da ordem de $1 \mathrm{cM}$ ou menor), também não pode ser totalmente descartada. A distinção entre as situações avaliadas somente será feita após sequenciamento gênico dos alelos alc e nor, o qual poderá então determinar como verdadeira uma das seguintes hipóteses:

- alc e nor são alélicos e idênticos entre si;

- alc e nor são alélicos, mas não idênticos entre si, conforme proposto por Lobo et al. (1984);

- alc e nor são não alélicos entre si, ligados a uma distância genética bastante pequena, da ordem de $1 \mathrm{cM}$.

A hipótese de alelismo entre alc e nor proposta por Lobo et al. (1984) foi aceita neste trabalho como a mais provável.

Uma nova simbologia para representar o genótipo alc/alc deve ser adotada. O genótipo alc/alc deveria passar a ser representado como $n o r^{A} /$ nor $^{A}$, ao invés de alc/alc, conforme sugestão inicial de Lobo et al. (1984). 
A hipótese de que alc e nor sejam genes distintos somente poderá ser admitida se também admitir que a distância entre esses genes seja da ordem de grandeza de $1 \mathrm{cM}$ ou menor.

\section{REFERÊNCIAS BIBLIOGRÁFICAS}

ANDRADE JUNIOR, V.C.; MALUF, W.R.; FARIA, M.V.; BENITES, F.R.G.; SANTOS JUNIOR, A.M. dos. Produção e qualidade de frutos de tomateiros portadores de alelos mutantes de amadurecimento e coloração. Pesquisa Agropecuária Brasileira, Brasília, v.40, n.6, p.555-561, 2005.

FARIA, M.V.; MALUF, W.R.; RESENDE, J.T.V.; ANDRADE JUNIOR, V.C. de; NASCIMENTO, I.R. do; BENITES, F.R.G.; MENEZES, C.B. de; AZEVEDO, S.M. de. Mutantes rin, nor ${ }^{\mathrm{A}}$, ogc e hp em diferentes backgrounds genotípicos de tomateiro. Pesquisa Agropecuária Brasileira, Brasília, v.41, n.5, p.793-800, 2006.

FREITAS, J.A.; MALUF, W.R.; GOMES, L.A.A.; AZEVEDO, S.M. Efeitos dos alelos alc og $^{\mathrm{c}}$ e hp sobre as características de maturação e conservação pós-colheita de frutos de tomateiro. Ciência e Agrotecnologia, Lavras, v.23, n.3, p.569-577, jul./set. 1998.
LOBO, M.; BASSET, M.J.; HANNAH, L.C. Inheritance and characterization of the fruit ripening mutation in "alcobaça" tomato. Journal of American Society for Horticultural Science, v.109, p.741-745, 1984.

MUTSCHLER, M.A. Inheritance and Linkage of the Alcobaça ripening mutant in tomato. Journal of American Society for Horticultural Science, Madison, v.109, p.500-503, 1984.

MUTSCHLER, M.A.; WOLFE, D.W.; COBB, E.D.; YOURSTONE, K.S. Tomato fruit quality and shelf life in hibrids heterozygous for the alc ripening mutanta.

HortScience, Alexandia, v.27, n.4, p.352-355, Apr. 1992.

SANTOS JUNIOR, A.M. dos; MALUF, W.R.; FARIA, M.V.; ANDRADE JUNIOR, V.C. de; NASCIMENTO, I.R. do; BENITES, F.R.G.; GOMES, L.A.A. Produção, qualidade e conservação de tomates heterozigotos nos locos alcobaça, nonripening e ripening inhibitor.

Pesquisa Agropecuária Brasileira, Brasília, v.40, n.12, p.1203-1210, 2005.

TIGCHELAAR, E.C.; BARMAN, R.J. Allelism of the alcobaça ripening mutant and nor. Tomato Genetics Cooperative Report, v.35, p.20-21, 1985. 